\title{
ANALYSIS OF Z-AXIS KINEMATICS INFLUENCE ON MEASUREMENT RESULT
}

\author{
Maciej Gruza' ${ }^{\text {, Wiktor Harmatys }}{ }^{1}$, Piotr Gąska ${ }^{1}$, Adam Gąska ${ }^{1}$, Jerzy Sładek${ }^{1}$ \\ 1 Laboratory for Coordinate Metrology (M-10), Faculty of Mechanical Engineering, Cracow University of \\ Technology, Jana Pawła II 37, 31-864 Kraków, Poland, e-mail: gruzam@interia.pl; wiktorharmatys@gmail.com; \\ pjgaska@gmail.com; agaska@mech.pk.edu.pl; sladek@mech.pk.edu.pl
}

Received: 2015.04.10

Accepted: 2015.05.08

Published: 2015.06.01

\begin{abstract}
CMMs accuracy depend on a number of factors. In spite of using various methods for CMM correction, the differences can be observed in the metrological capability between the areas in the measuring volume of CMM. Authors attempted to estimate the impact of one of potential CMM accuracy influencing factors, a CMM Z-axis position during measurement, on measurement result. This article presents performed experiments and obtained results.
\end{abstract}

Keywords: CMM accuracy, CMM kinematics.

\section{INTRODUCTION}

The importance of the Coordinate Measuring Technique (CMT) in today's dimensional metrology has been steadily increasing. It is successfully used in many branches of industry around the world. Measurements using a Coordinate Measuring Machines become invaluable especially when measurement automation is required, as well as their high accuracy. Furthermore, a growing number of CMT users recognize the necessity of the measurement uncertainty estimation and the traceability assurance. Reputable research centres conduct studies aimed at better understanding of phenomena that occur during coordinate measurements. They try to disseminate knowledge about the components of the measurement uncertainty and implement the results of their experiences into industrial practice. Especially in recent years, it has brought tangible benefits to both parties. This way research laboratories can validate their research results, while cooperating companies often without bearing the costs, gain new technological solutions, which may improve accuracy of the measurement or reduce its duration. Currently, due to technical constraints and insufficient knowledge, many components of the measurement uncertainty cannot be precisely determined, however, their impact on the measurement accu- racy may be at least estimated. The method which is based on experience and involves estimation of the impact of individual components on measurement accuracy is called the error budget. It is a method that requires extensive knowledge and long-standing practice, thus it is hard to apply on a larger scale, the application can be found mainly in calibration laboratories. The error budget can be utilized also for the so-called Virtual machine preparation. This solution allows multiple on-line simulation of measuring task. Results obtained in such a way can be then utilized during uncertainty estimation for example using methods of statistical analysis [1].

The most important part of the implementation of the virtual machine is the development phase which involves appropriate experiments aimed at identification of the main sources of errors that may occur during measurement. Virtual machine is usually based on several modules which model the major errors' contributors, such as machine kinematics errors and errors of the probe head. However, the machine should be also tested thoroughly for other factors and continuously developed. In this paper, the authors describe the experiment that was conducted in order to estimate the impact of the measured object position in the measuring volume of CMM on the measurement results. 


\section{THE COORDINATE MEASURING MACHINES AND ERRORS ASSOCIATED WITH THEIR FUNCTIONING}

In CMT, data in a form of measured points coordinates is collected from the surface of the measured object. Sampled coordinates are then used for determination of dimensions of spatial shaped objects [2]. Measuring points can be gathered using different devices and utilizing various methods. The main tool of CMT is a Coordinate Measuring Machine (CMM). In conventional CMMs the kinematic pairs shift in mutually perpendicular directions, which define the axes X, Y and $\mathrm{Z}$ of the machine base Cartesian coordinate system. The machine movements in each axis are measured using linear scales. Essential element of each CMM is a probe head which provides a connection between measuring system and the measured object [3].

The machines may differ in construction and the methods used for probing. Methodology described in this paper refers to the CMMs with moving bridge and tactile probe head. The CMMs of such a type are commonly used in industry, moreover, they were also subject of a number of research programs. The main sources of errors are derived from machine kinematics and functioning of probe heads. The kinematics errors are associated with 21 components of geometrical errors which constitute so-called rigid body model of kinematic errors, further information on this subject can be found in [4]. The kinematic errors can be significantly reduced using different compensation methods for instance the Computer Aided Accuracy (CAA) matrix. In turn, probe head errors arise mainly due to phenomena related to the probe head work principle such as pretravel [5]. Additionally, probe heads are prone to errors connected with interactions between the measured surface and the tip ball [6].

The probe heads qualification process is used in order to minimize the above-mentioned influences. Other factors affecting the accuracy of the machines are the errors associated with the measurement dynamics [7]. During measurements performed on any CMM certain dynamic phenomena occur due to the movement of elements of a large masses. Between the measuring points the machine moves with high speed. Whereas the contact process itself is more complex and can be divided into four main stages: the approach of the tip ball with constant speed to the measuring surface, tip ball contact with measuring surface, identification of contact point position, retract from the measured surface. Different probing parameters, such as: probing speed, acceleration and approach distance have a substantial impact on the measurement results. The authors suspect that the location of the measured object in the measuring volume of the machine also contributes to the CMM errors. The experiment that is shown in this paper was conducted in order to estimate how changes in position of spherical standard would affect the measurement accuracy

\section{EXPERIMENT AND RESULTS}

In this study, the authors intended to investigate the errors associated with the z-axis kinematics. The experiment procedure involved measurements of the spherical standard which was positioned at selected locations in machine's measuring volume, in such a way that all possible measurement conditions would remain unchanged. An essential element of studies was to find a suitable holder, which would allow to change the position of a standard in the z-axis of CMM.

All measurements were performed on the ZEISS WMM 850S machine which is placed at Laboratory of Coordinate Metrology in Cracow University of Technology. During the measurements the machine was equipped with Renishaw PH10M articulated probe head with mounted TP20 STD probe. The ambient conditions were constantly monitored and during the whole experiment the temperature was at level of $20 \pm 0.5^{\circ} \mathrm{C}$. The probing parameters were not changed between measurements. The spherical standard of 24.9946 $\mathrm{mm}$ which meets the requirements of form error according to [8] was used. As an attachment the holder for KOBA step gauge was chosen, due to its technical solutions and stability. It allows to fix a standard on eight different heights and adjust the tilt axis of the column. Three positions of the standard were used in experiment: the lowest and the highest possible height, and an intermediate position. The difference between the extreme heights was greater than half of the working range of the $\mathrm{z}$ axis. The three positions of the standard are shown on the Figure 1.

The standard sphere was measured at 82 points distributed evenly over the surface of the upper hemisphere of the standard. The location of measuring points was specified using two angles 


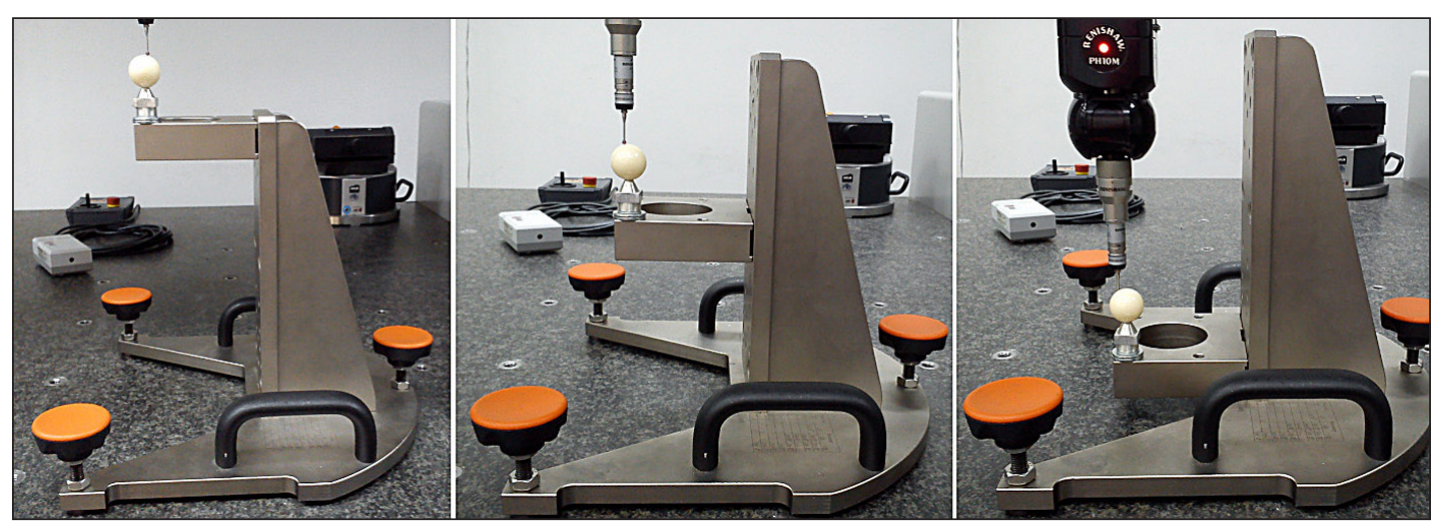

Fig. 1. The three positions of the standard during measurements
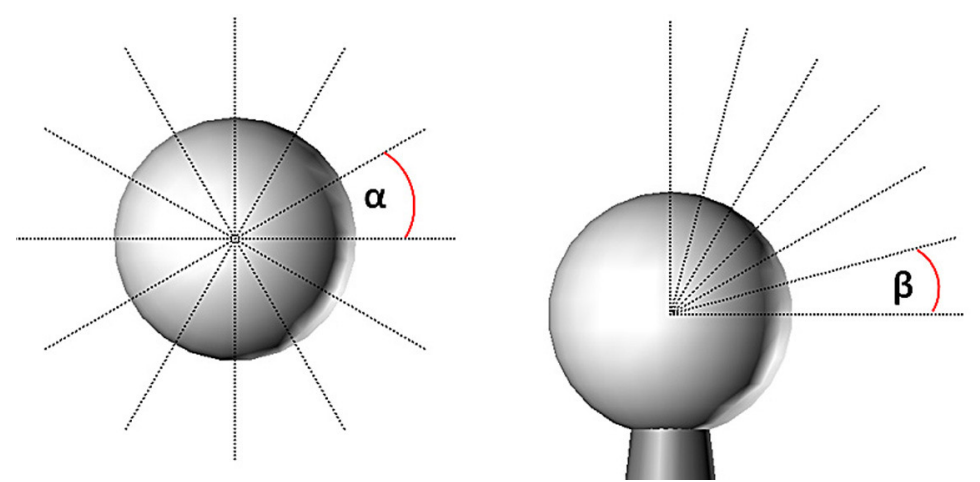

Fig. 2. The horizontal $\alpha$ and vertical beta $\beta$ angles, which define measuring points

- horizontal and vertical $\left(\alpha=40^{\circ}, \beta=10^{\circ}\right)$. The angles definition is presented in Figure 2.

The measurement sequence was repeated ten times in each of the standard positions. The measured sphere was evaluated in terms of diameter and sphericity deviation. Obtained results are presented in Table 1 and Table 2.

Additionally, in order to determine the distribution of errors the graphs that represents mean values of errors for each position was prepared (Figs. 3-5).

Table 1. The measured diameter for three positions of the standard

\begin{tabular}{|l|c|c|}
\hline \multicolumn{1}{|c|}{ Position } & $\begin{array}{c}\text { Mean } \\
{[\mathrm{mm}]}\end{array}$ & $\begin{array}{c}\text { Standard deviation } \\
{[\mathrm{mm}]}\end{array}$ \\
\hline The lowest position & 24.9963 & 0.00020 \\
\hline The intermediate position & 24.9975 & 0.00046 \\
\hline The highest position & 24.9966 & 0.00015 \\
\hline
\end{tabular}

Table 2. The measured sphericity for three positions of the standard

\begin{tabular}{|l|c|c|}
\hline \multicolumn{1}{|c|}{ Position } & $\begin{array}{c}\text { Mean } \\
{[\mathrm{mm}]}\end{array}$ & $\begin{array}{c}\text { Standard deviation } \\
{[\mathrm{mm}]}\end{array}$ \\
\hline The lowest position & 0.0051 & 0.00046 \\
\hline The intermediate position & 0.0060 & 0.00048 \\
\hline The highest position & 0.0079 & 0.00023 \\
\hline
\end{tabular}

\section{CONCLUSIONS}

On all the prepared graphs a characteristic distribution of errors with three positive and three negative extremes can be observed. Probably, it is caused by the construction of TP2 0 probe. In this solution the stylus is combined with three arms, which are oriented relative to each other by 120

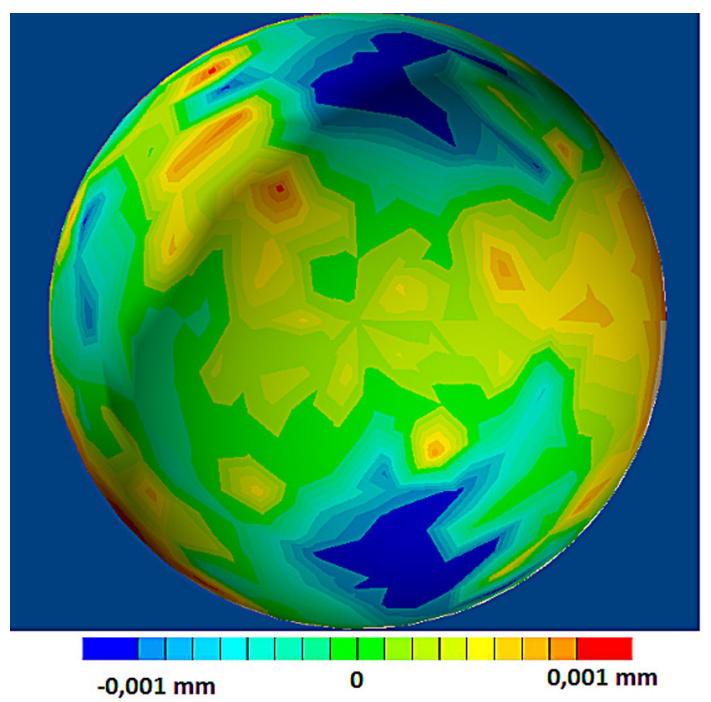

Fig. 3. The errors distribution for the lowest standard position 


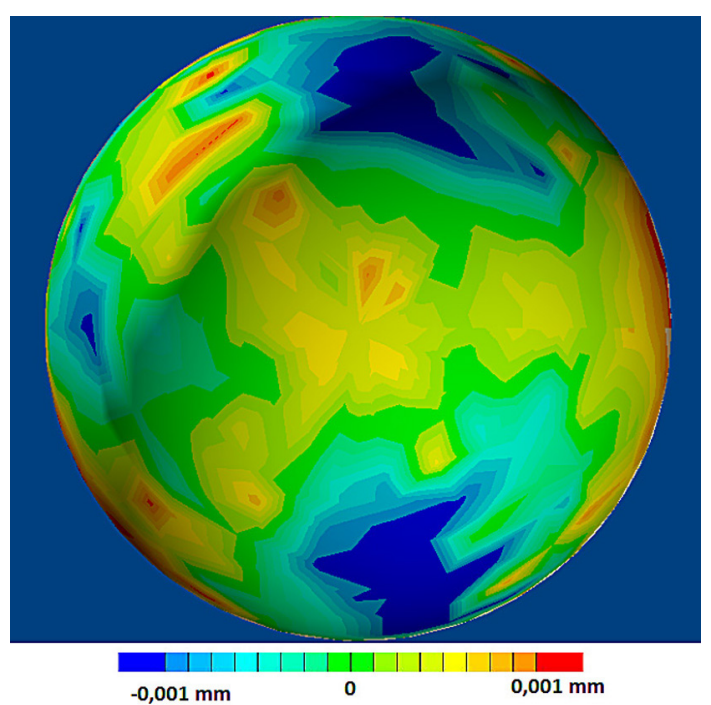

Fig. 4. The errors distribution for the intermediate standard position

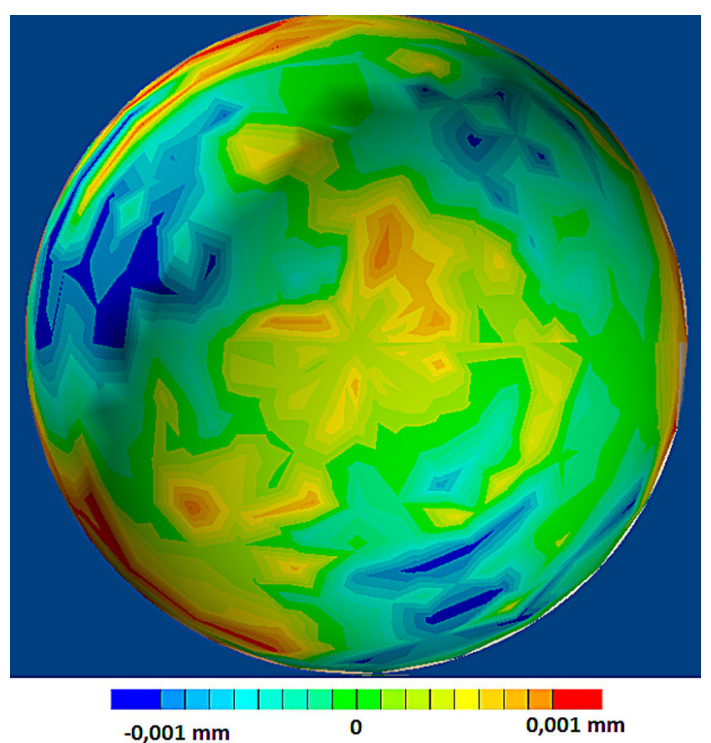

Fig. 5. The errors distribution for the highest standard position

degrees, and ended spherically. The spring presses arms to a prisms on which they rely. The contact impulse is generated when one of the arms lose contact with the prism and the electrical circuit is broken. The biggest errors were obtained at the equator of the standard.

The results presented in the Table 1 and Table 2 are not unequivocal. The diameters obtained for different positions did not differ significantly. The authors suspect that the results would be noticeably worse for the lowest location of the standard, because the $\mathrm{z}$ axis of the machine would be ejected the farthest. The results obtained for the sphericity suggest a completely the opposite conclusion. Perhaps the obtained results might be caused by the quill counterbalance system. On the other hand, the values of standard deviation for both parameters for this position are the smallest, what indicates that the machine works stably with low ejection of the quill.

The presented results are consistent with the experience of LCM, regarding the calibration of CMMs working in industrial conditions. Although, the obtained results are interesting, additional studies ought to be undertaken in order to draw more definitive conclusions.

\section{Acknowledgements}

Reported research was realized within confines of project financed by Polish National Center for Research and Development No: LIDER/06/117/L-3/11/NCBR/2012.

\section{REFERENCES}

1. Gąska A.: Modeling the accuracy of coordinate measurement with use of Monte Carlo method. Ph.D. Dissertation, Cracow University of Technology, 2011.

2. Sładek J. Accuracy of coordinate measurements. Cracow University of Technology, Cracow 2013.

3. Weckenmann A., EstlerT., PeggsG., McMurtryD.: Probing systems in dimensional metrology. CIRP Annals-Manufacturing Technology, 53, 2, 657-684.

4. Gąska A., Gruza M., Gąska P., Karpiuk M., Sładek J.: Identification and correction of coordinate measuring machine geometrical errors using Laser Tracer systems. Advances in Science and Technology Research Journal, 7, 20, 2013, 17-22.

5. Hocken R.J., Pereira P.H. (eds.): Coordinate measuring machines and systems. Second edition, CRC Press, 2012.

6. Sładek J.:Modelowanie i ocena dokładności maszyn oraz pomiarów współrzędnościowych. Praca habilitacyjna. Wydział Mechaniczny, Politechnika Krakowska, 2001.

7. Weekers W.G., Schellekens P.H.J.: Compensation for dynamic errors of coordinate measuring machines. Measurement 20, 3, 1997, 197-209.

8. ISO 10360 part 5, 2010. CMMs using single and multiple stylus contacting probing systems. Second edition. 